\title{
Gramática de Libras: perspectivas terminológicas sobre a fonologia
}

\author{
Silvana Alves CARDOSO (1) \\ Universidade Federal de Pernambuco (UFPE)
}

RESUMO

A conferência, intitulada Gramática de Libras, proferida pela professora Dr. ${ }^{a}$ Ronice Quadros diz respeito à apresentação de uma proposta de sistematização gramatical para os fenômenos linguísticos presentes na Libras, materializada, por sua vez, totalmente em Libras, e com tradução de voz para a Língua Portuguesa. Trata-se de um projeto que objetiva, entre outras questões, a produção de uma primeira gramática da Libras, o registro da Libras e a socialização de trabalhos desenvolvidos por linguistas nessa área. Nela, estão presentes os fenômenos de diversos componentes linguísticos (Fonologia, Morfologia, Sintaxe etc.) constatados e estudados nos trabalhos realizados por surdos de diferentes regiões do Brasil.

OPEN ACCESS

EDITADO POR

Raquel Freitag

AVALIADO POR Rodrigo Machado

DATAS

Recebido: 08/07/2020

Aceito: $23 / 10 / 2020$ Publicado: 29/10/2020

COMO CITAR

Cardoso, S. A. (2020). Gramática de Libras: perspectivas terminológicas sobre a fonologia. Revista da Abralin, v. 19, n. 2, p. 1-4, 2020.

\section{ABSTRACT}

The conference, entitled Gramática de Libras, given by Professor Dr. ${ }^{\text {a }}$ Ronice Quadros concerns the presentation of a proposal for grammatical systematization for the linguistic phenomena present in Libras, materialized, in turn, entirely in Libras, and with translation of voice for the Portuguese language. It is a project that aims, among other issues, the production of a first grammar of Libras, the registration of Libras and the socialization of works developed by linguists in this area. In it, the phenomena of several linguistic components (Phonology, Morphology, Syntax etc.) are found and studied in the works carried out by deaf people from different regions of Brazil. 


\section{REVISTA DA ABRALIN}

PALAVRAS-CHAVE

Libras. Gramática. Descrição.

\section{KEYWORDS}

Libras. Grammar. Description.

Desde o surgimento dos primeiros estudos sobre línguas de sinais de um modo geral, historicamente iniciados com as pesquisas de William Stokoe (1960), os linguistas e estudiosos vêm desempenhando um árduo trabalho na tentativa de analisar, descrever e sistematizar os mais variados fatos linguísticos presentes nessas línguas. No Brasil, a obra pioneira Por uma gramática de línguas de sinais (1995), de Lucinda Ferreira Brito, é, por exemplo, um desses empreendimentos descritivos, em termos de pensar uma gramática para a Língua de Sinais Brasileira (Libras).

A proposta Gramática de Libras, apresentada pela professora Dr. ${ }^{a}$ Ronice Müller de Quadros na conferência do Abralin ao Vivo, também se configura como uma dessas tentativas, todavia com um caráter bastante interessante e inovador, tendo em vista que trabalhos descritivos anteriores tomavam a Língua Portuguesa como metalinguagem na caracterização dos fenômenos linguísticos: diferentemente, Quadros, que é uma pesquisadora reconhecida na área da Libras, e atualmente professora da Universidade Federal de Santa Catarina (UFSC), propõe uma descrição gramatical da Libras em Libras. De acordo com a idealizadora, essa nova perspectiva, identificada como gramática tipológico-funcional e composta por dados de produção espontânea, tem como pretensão principal estabelecer, a partir de um Corpus de Libras, a primeira gramática diretamente em Libras, além de assegurar o registro da Libras e a socialização dos trabalhos desenvolvidos nessa área.

Assim, a Gramática de Libras - apoiada pelo Conselho Nacional de Desenvolvimento Científico e Tecnológico (CNPq) e Instituto do Patrimônio Histórico e Artístico Nacional (IPHAN), e com tradução em voz para o português e lançamento previsto para o corrente ano - não se configura como um projeto solitário, mas uma proposta coletiva que envolve os dados dos estudos de trinta e cinco informantes surdos de referência nas regiões do território brasileiro. Dentre esses dados (organizados por meio de glosas a partir da ferramenta de transcrição ELAN), a conferencista evidencia casos de fenômenos característicos de alguns dos componentes linguísticos que formam a Gramática de Libras, a saber, construção dos sinais, variações do léxico, neologismos, entre outros no campo fonológico e morfológico; e ordem e reordenação sintática, contextos de coordenação (parataxe) e de subordinação (hipotaxe) etc. no campo sintático.

De fato, a gramática em realce mostra-se como um importante instrumento de autonomia e reposicionamento da Libras no âmbito das pesquisas linguísticas, atenuando cada vez mais o laço comparativo-descritivo entre os fenômenos visuais e os das línguas orais. E é nesse ensejo que questões de cunho terminológico devem ser olhadas com maior atenção nesse novo modo de fazer a gramática da Libras, pois, como ressalta Benveniste (1989, p. 252), “a constituição de uma 


\section{REVISTA DA ABRALIN}

terminologia própria marca, em toda ciência, o advento ou o desenvolvimento de uma conceitualização nova, assinalando, assim, um momento decisivo de sua história". Portanto, a precisão terminológica é, também, um aspecto exigido pelo fazer científico enquanto constatação linguística, uma vez que tão necessário e importante quanto à descoberta dos constituintes de uma língua é a sua devida nomeação.

Nessa direção, encontram-se, na literatura especializada da área, cada uma representando, portanto, a percepção teórica/discursiva do seu proponente, algumas propostas de atualização da nomenclatura para o campo da, conhecida, Fonologia da Libras, no que diz respeito aos termos da tradição oral (e de raiz etimológica sonora) Fonologia e Fonema, como forma de levantar a reflexão sobre o emprego de termos que melhor representam a realidade linguístico-modal dos elementos da Libras, são elas: Visologia e Visema, de Mariângela Barros (2008); SematosEma e SematosEmia, de Fernando Capovilla (2015); Signema e Sigmanulogia, de Valdo Nóbrega ${ }^{1}$ (2016); Sinema e Sinologia ${ }^{2}$, de Vicente Masip (2019). Embora existam tais perspectivas terminológicas, a preferência continua a ser pelos termos conservadores cunhados para os estudos das línguas orais, com a justificativa de estarem adotando as mesmas nomenclaturas para atender e não se distanciar da tradição conceitual linguística já consolidada.

Muito além da ideia da partilha de universais linguísticos e da referência a elementos mínimos abstratos presentes tanto nas línguas orais quanto nas línguas de sinais, essa preferência revela ainda, por outro lado, a força hegemônica das línguas orais, tidas como majoritárias, sobre as línguas de sinais, consideradas minoritárias, evidenciando a influência político-discursiva, de natureza social, das primeiras, que asseguram (e, por que não, impõem), por vezes, a preservação dos termos nas investigações linguísticas das últimas. Porém, como ainda se trata da primeira edição da proposta Gramática de Libras, e, por certo, haverá, conforme Quadros, outras versões, a temática do aperfeiçoamento terminológico é um forte candidato a ser repensado e contemplado nesse novo recurso que busca registrar e resguardar os aspectos naturais e particulares da Libras.

\section{REFERÊNCIAS}

BARROS, Mariângela Estelita. ELiS - Escrita das Línguas de Sinais: proposta teórica e verificação prática. 2008. Tese (Doutorado). Universidade Federal de Santa Catarina. Florianópolis. 2008.

BENVENISTE, Émile. Problemas de linguística geral. Tradução de Maria da Glória Novak e Luiza Neri. Revisão do Prof. Isaac Nicolau Salum. São Paulo: Editora da Universidade de São Paulo, 1976.

1 Valdo Ribeiro da Nóbrega, surdo, professor de Libras da Universidade Federal da Paraíba.

2 Em andamento, por meio da pesquisa intitulada A dimensão Significante da Língua Brasileira de Sinais, sob do aval da PROPESQ UFPE. 


\section{REVISTA DA ABRALIN}

CAPOVILLA, Fernando César. Paradigma neuropsicolinguístico para refundação conceitual e metodológico da linguagem falada, escrita e de sinais para alfabetização de ouvintes, deficientes auditivos, surdos e surdocegos. In: CAPOVILLA, Fernando César; RAPHAEL, Walkiria Duarte; MAURÍCIO, Aline Cristina L. (Org.). Novo Deit-Libras: Dicionário Enciclopédico Ilustrado Trilíngue da Lingua de Sinais Brasileira (Libras) baseado em Linguística e Neurociências Cognitivas. Vol. I: (sinais de A a H). $3^{\text {a }}$ edição (ver. e ampl.). São Paulo: editora da Universidade de São Paulo, 2015.

FERREIRA. Lucinda. Por uma gramática de línguas de sinais. [reimpr.]. Rio de Janeiro: Tempo Brasileiro, 2010.

GRAMÁTICA de Libras. Conferência apresentada por Ronice Müller de Quadros. [S.l.: s.n.], 2020.1 vídeo (1h08min25seg). Publicado pelo canal da Associação Brasileira de Linguística. Disponível em: https://www.youtube.com/watch?v=yT7Z0y4_n3U. Acesso em: 03 de julho de 2020.

NÓBREGA, Valdo Ribeiro Resende da. Sigmanulogia: proporcionando uma teoria linguística da língua de sinais. Revista Leitura, Alagoas, v.1, n. 57, p. 198-218, 2016.

STOKOE, William C. Sign language structure. Reedição. Silver Spring, Maryland: Linstok Press, 1960. 